\title{
ALUCINACIONES VISUALES SECUNDARIAS AL TRATAMIENTO CON CIPROFLOXACINO
}

\section{VISUAL HALLUCINATIONS SECONDARY TO CIPROFLOXACIN TREATMENT}

\author{
ASENSIO-SÁNCHEZ VM ${ }^{1}$, RODRÍGUEZ-DELGADO B ${ }^{1}$, GARCÍA-HERRERO E ${ }^{2}$, \\ CABO-VAQUERA V ${ }^{2}$, GARCÍA-LOYGORRI C ${ }^{1}$
}

\section{RESUMEN}

Caso clínico: Se describe el caso de una mujer de 74 años que tuvo alucinaciones visuales después de la administración de ciprofloxacino cuando estaba tomando una teofilina, resolviéndose el cuadro alucinatorio cuando se suspendió el ciprofloxacino.

Discusión: Aunque es poco frecuente, todos los oftalmólogos deberían estar alerta y conocer los posibles efectos adversos visuales en pacientes con tratamiento simultáneo de quinolonas y teofilinas.

Palabras clave: Quinolonas, ciprofloxacino, teofilinas, alucinaciones visuales, politratamientos.

\section{INTRODUCCIÓN}

Las alucinaciones son percepciones sensoriales sin estímulo externo que cuando afectan al sentido de la vista se denominan alucinaciones visuales (1). Pueden ser simples (fosfenos) o complejas (caras, paisajes). Las alucinaciones visuales no son infrecuentes en determinados estados psiquiátricos, en enfermeda- des neurológicas, y después del uso y abuso de drogas (1). Los pacientes con ciertos procesos neuro-oftalmológicos pueden presentar alucinaciones (2). Los medicamentos, incluso a dosis terapéuticas, también pueden ser responsables de alucinaciones visuales en sujetos normales. Se describe el caso de una paciente que experimentó alucinaciones visuales complejas después de la administración de ciprofloxacino.

Recibido: 11/5/06. Aceptado: 21/3/07.

Hospital General. Medina del Campo. Valladolid. España.

1 Doctor en Medicina.

2 Licenciado en Medicina.

Correspondencia:

V.M. Asensio-Sánchez

Hospital General del SACYL

Medina del Campo (Valladolid)

España

E-mail: vasensio@hmdc.sacyl.es 


\section{CASO CLÍNICO}

Mujer de 74 años de edad ingresada en el servicio de medicina interna por un tromboembolismo (TEP) pulmonar que precisó oxigenoterapia, anticoagulación con sintrom y teofilina (theolair ${ }^{\circledR}$ ) a dosis de $12 \mathrm{mg} / \mathrm{kg}$ día. A las 72 horas del ingreso al tratamiento base se añadió ciprofloxacino intravenoso $200 \mathrm{mg}$ cada 12 horas. Casi 24 horas después del nuevo tratamiento la paciente refirió que veía puntos negros brillantes que «flotaban» por toda la habitación. La tomografía axial computerizada (TAC) cerebral no detectó patología por lo que se pidió interconsulta a oftalmología para «descartar accidente vascular retiniano». La paciente empezó a ver diferentes figuras geométricas (círculos, pentágonos y triángulos) en colores mezcladas con hojas verdosas que flotaban por la habitación. Al mismo tiempo veía a sus familiares pero sin cabezas, que habían sido sustituidas por las figuras triangulares. Cuando se la exploró estaba bien orientada temporo-espacialmente pero presentaba un gran estado de ansiedad, la agudeza visual no se pudo establecer en ese momento pues «un cuadro amarillo con manchas verdes tapaba las letras» (fig. 1), la tensión ocular fue de $16 \mathrm{mmHg}$ en cada ojo, siendo normales la motilidad ocular extrínseca e intrínseca y la biomicroscopía anterior y posterior. Una resonancia magnética nuclear (RMN) cerebral con gadolinio fue normal así como una RMN por difusión. La exploración neurológica no fue relevante. Ante la sospecha de un fenómeno tóxico por ciprofloxacino se suspendió del tratamiento. Las alucinaciones

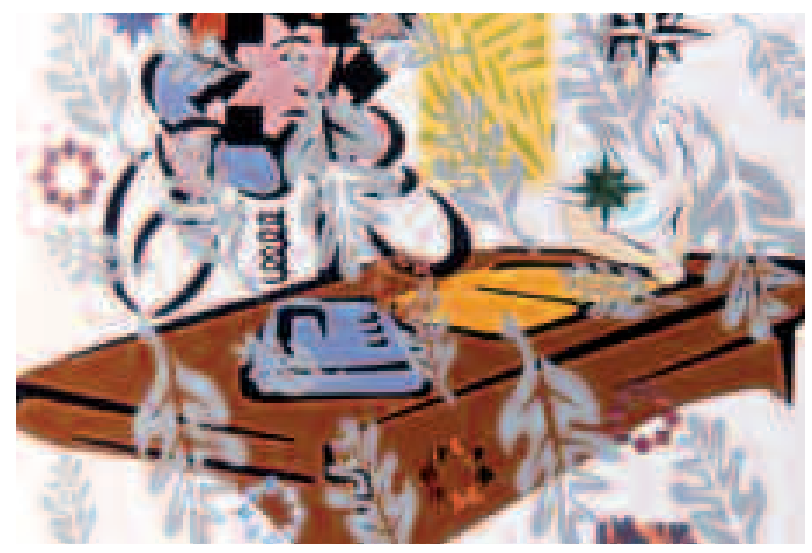

Fig. 1: Reconstrucción gráfica de cómo la paciente veía la consulta de oftalmología en el momento de la exploración. El cuadro lo experimentó con una gran ansiedad $y$ angustia. persistieron unas 36 horas con resolución completa. El estudio psiquiátrico de la paciente no detectó patología.

\section{DISCUSIÓN}

El Ciprofloxacino es un antibiótico del grupo de las fluoquinolonas y es uno de los antimicrobianos que más se prescriben actualmente en todas las especialidades médicas y quirúrgicas. Generalmente es bien tolerado por los pacientes con muy pocos efectos secundarios, siendo los más frecuentes cutáneos, gastrointestinales y en el sistema nervioso central con una incidencia entre el $0,4 \%$ y el $4,4 \%$, destacando mareos y cefaleas (3). La descripción de alucinaciones visuales, aunque poco frecuente, es mayor que hace unos años por el abuso de estos antibióticos tanto en medio hospitalario como extra-hospitalario y porque su acción tóxica se ve potenciada, incluso a dosis terapéuticas, por la polimedicación de la mayoría de estos pacientes. Segev et al (3) establecen en un estudio experimental que las fluoquinolonas desplazan al ácido gamma-aminobutírico (GABA) de su receptor, resultando en la excitación general del sistema nervioso central, siendo ésta la base de este efecto adverso. La combinación de teofilinas y fluoquinolonas tendría un efecto aditivo. En este trabajo se describe el caso de una mujer que experimentó alucinaciones visuales complejas después de la administración de ciprofloxacino, que cesaron al retirar el tratamiento antibiótico. La paciente estaba tratada con una teofilina a dosis terapéuticas pero no obstante potenció el efecto del ciprofloxacino.

Davies et al (4) en 80 pacientes tratados con ciprofloxacino por bronquitis crónica purulenta describen ocho casos de náuseas, dolor de estómago y alucinaciones. Farrington J et al (5) describen una paciente de 40 años que desarrolló un cuadro de desorientación y agitación con alucinaciones visuales secundario a ciprofloxacino. Todos los médicos y especialmente los oftalmólogos, que son consultados ante estos problemas, deben estar alerta de este posible efecto secundario de las fluoquinolonas. Las alucinaciones visuales aunque pueden ocurrir son raras en los pacientes que están tomando sólo quinolonas pero no son infrecuentes en los que están polimedicados especialmente en pacientes con teofilinas (3), fármacos de prescripción muy frecuente e incluso crónica. 


\section{BIBLIOGRAFÍA}

1. Andreasen N, Hyler SE, Maxmen JS, Sharpe L, Sheehy M, Spitzer RL et al. DSM-III. Manual diagnóstico y estadístico de los trastornos mentales. Barcelona: Masson; 1983: 370-371.

2. Asensio-Sánchez VM, Merino-Núnez $F$, Rivas-Pastoriza A. Alucinaciones visuales complejas en un paciente con déficit visual severo en ambos ojos (Síndrome de Charles Bonnet). Arch Soc Esp Oftalmol 2003; 78: 327-329.
3. Segev S, Rehavi M, Rubinstein E. Quinolones, theophylli$n e$, and diclofenac interactions with the gamma-aminobutyric acid receptor. Antimicrob Agents Chemother 1988; 32: 1624-1626.

4. Davies BI, Maesen FP, Baur C. Ciprofloxacin in the treatment of acute exacerbations of chronic bronchitis. Eur J Clin Microbiol 1986; 5: 226-231.

5. Farrington J, Stoudemire A, Tierney J. The role of ciprofloxacin in a patient with delirium due to multiple etiologies. Gen Hosp Psychiatry 1995; 17: 47-53. 